Нургалиева М. Б.

РОЛЬ СОВРЕМЕННЫХ МУЗЕЕВ В ФОРМИРОВАНИИ МЕХАНИЗМОВ НАСЛЕДОВАНИЯ ТРАДИЦИЙ

ЭТНОКУЛЬТУРНОГО МНОГООБРАЗИЯ (ПО МАТЕРИАЛАМ РОССИЙСКИХ МУЗЕЕВ ЗА 2012-2017 ГОДЫ)

Нургалиева М. Б.

M. B. Nurgalieva

РОЛЬ СОВРЕМЕННЫХ МУЗЕЕВ В ФОРМИРОВАНИИ МЕХАНИЗМОВ НАСЛЕДОВАНИЯ ТРАДИЦИЙ ЭТНОКУЛЬТУРНОГО МНОГООБРАЗИЯ (ПО МАТЕРИАЛАМ РОССИЙСКИХ МУЗЕЕВ ЗА 2012-2017 ГОДЫ)

\title{
THE ROLE OF MODERN MUZEUMS IN THE MECHANISM FORMATION FOR TRADITION INHERITANCE OF ETHNIC AND CULTURAL DIVERSITY (BASED ON THE MATERIALS OF RUSSIAN MUSEUMS IN 2012-2017)
}

Нургалиева Марина Борисовна - директор Музейно-выставочного центра г. Находки, аспирантка Школы искусств и гуманитарных наук Дальневосточного федерального университета (Россия, Владивосток); тел.: +7 (914) 716-57-78. E-mail: marin-nakhodka@mail.ru.

Ms. Marina B. Nurgalieva - Director of the Museum and exhibition center of Nakhodka, a postgraduate student, School of Arts and Humanities, Far Eastern Federal University (Russia, Vladivostok); tel.: +7 (914) 716-57-78. E-mail: marin-nakhodka@mail.ru.

Аннотация. В статье рассматривается вопрос о деятельности современных музеев по разработке механизмов наследования традиций этнокультурного многообразия и о повышении роли музеев в трансляции этнического наследия, используются при этом новые механизмы и технологии. Автор статьи изучает основные тенденции по использованию новых форм деятельности музея за 2012-2017 годы в трансляции этнокультурного наследия, описанные исследователями в области музейного дела. В статье приводятся примеры наиболее успешных практик российских музеев за последние 5 лет, обозначаются наиболее перспективные направления работы музея в данном направлении.

Summary. The article considers the issue of the activities of modern museums in creating mechanisms for the inheritance of traditions of ethnocultural diversity and enhancing the role of museums in translating ethnic heritage using new mechanisms and technologies. The author of the article studies the main trends in 2012-2017 concerning the use of new museum forms in the translation of the ethnocultural heritage, described by researchers in the field of museum business. The article provides examples of the most successful practices of Russian museums over the past 5 years, and identifies the most promising areas of work of the museum in this direction.

Ключевые слова: механизмы наследования, музей, музейное дело, этнокультурное многообразие.

Key words: ethno-cultural heritage, Museum practices, broadcasting mechanisms, ethnic expositions.

УДК 069

Усиление миграционных процессов в России привело к расширению этнокультурного многообразия, которое, в свою очередь, может стать одним из факторов дестабилизации современного общества. Новая «Стратегия государственной национальной политики Российской Федерации на период до 2025 года», принятая указом Президента РФ в 2012 году, сегодня играет важную роль в формировании этнокультурной политики в России» $[1,32]$. В этом документе прописана роль музея как важнейшего института, выполняющего функции сохранения и интерпретации этнокультурного наследия.

Большинство исследователей отмечает, что наступивший XXI век характеризуется качественно новым этапом в этнокультурном развитии макросоциальной среды. «Обострение межэтнических отношений способно привести к возникновению этнических конфликтов. В данных условиях особое значение приобретает деятельность музеев, способных оказать реальную помощь по преодолению этнокультурных барьеров» $[2,128]$.

Способность музея сохранять чувство идентичности приходящих в него людей осуществляется благодаря его исторически сложившимся социокультурным функциям, таким как трансля- 


\section{Учёные записки}

Комсомольского-на-Амуре государственного технического университета

ция культуры народа или определённой местности. Музейное сообщество осмысливает проблемы, вызванные процессами глобализации, ищет пути их решения в музейной сфере.

Одной из важнейших функций этнокультурного наследия, большая часть которого сосредоточена в музеях, является поддержка в информационном обществе культурного многообразия, а потому оно представляет и создаёт оптимальные условия для культурной самоидентификации. «Значительная доля музейных коллекций и экспозиций, имеющих отношение к этнокультурному наследию, сформирована весьма давно, и они отражают уже не вчерашний, а позавчерашний день. Важно не только сохранить в первозданном виде, но и активно включить музейные коллекции в канву современной жизни» $[6,17]$.

Механизмы презентации этнической культуры наделяют музеи особым статусом в деле сохранения и трансляции накопленного человеческого этнического опыта. В качестве таких механизмов в данной работе мы рассматриваем музейную деятельность, различные формы экспозиционной и просветительской работы музея.

Объект исследования статьи - этнокультурное многообразие, отражённое в музеях России. Предмет исследования - механизмы наследования традиций этнокультурного многообразия в современном музее РФ. Цели исследования данной работы: рассмотреть деятельность современных музеев по разработке механизмов наследования традиций этнокультурного многообразия в трансляции этнического наследия за 2012-2017 годы, выявить наиболее успешные практики российских музеев за последние 5 лет.

Обратимся к понятию «современный музей». В этом нам помогут теоретические принципы, заложенные «Новой музеологией». Это направление мировой музеологии, возникшее в 1980-х гг. и рассматривающее музеи прежде всего как форму, нацеленную на решение актуальных проблем местного сообщества, способствует его интеграции в окружающую среду. «Формы и методы создания музеев, заданные “Новой музеологией”, направлены на музеефикацию и актуализацию культурного материального, движимого и недвижимого, и нематериального наследия, а также природного, при непосредственном участии общества или общественных инициатив в деятельности музея» $[7,320]$.

Исследователи М. С. Каган, 3. А. Бонами, Т. П. Калугина определили основную функцию современного музея - хранение и передача внегенетического опыта или «механизм культурного наследования», тем самым поставив музей в один ряд с архивами, библиотеками, системой образования и искусством $[5,75]$.

Проблемы представления традиционной культуры разных народов в современном музее в своих работах рассматривает фольклорист, этнограф О. Р. Николаев. Он считает, что традиционная культура в советскую эпоху была вытеснена псевдонародной культурой и нуждается в реабилитации. Французский музеолог Жермен Вьят предостерегает: «Давайте избегать упрощений, которые бывают весьма заманчивы в отношении другого. Кроме того, если музей как педагогический инструмент участвует в образовании детей, он не должен становиться упрощённым и наивным» $[3,27]$.

С представлением традиционной культуры в российских музеях особых проблем, казалось бы, нет. Вместе с тем инерция стандартных подходов к репрезентации традиционной культуры настолько сильна, что в этой сфере редко появляются инновационные идеи.

Рассмотрим экспозиционно-выставочную деятельность музея, которая презентует хранящиеся в фондах музейные предметы, возвращая их в нашу повседневность, но уже в преображённом виде. Этнографические экспозиции сосредоточены исключительно на объектах материальной культуры с обязательной доминантой на представлении сельскохозяйственных занятий. Можно привести несколько новых подходов в построении музейных экспозиций, связанных с этническими традициями:

- В проекте «Путешествие в страну людиков» (2012) пространство на выставке было организовано вокруг «оси мира». Для традиционного человека место, где он живёт, всегда должно быть уподоблено «центру мира». «Осью мира» стал «стожар»- конструкция из жердей и кольев, 
Нургалиева М. Б.

РОЛЬ СОВРЕМЕННЫХ МУЗЕЕВ В ФОРМИРОВАНИИ МЕХАНИЗМОВ НАСЛЕДОВАНИЯ ТРАДИЦИЙ

ЭТНОКУЛЬТУРНОГО МНОГООБРАЗИЯ (ПО МАТЕРИАЛАМ РОССИЙСКИХ МУЗЕЕВ ЗА 2012-2017 ГОДЫ)

вокруг которой строится стог. А сам построенный стог имеет форму яйца (универсальный космогонический символ) [1].

- Проект новой экспозиции Музея хлеба (Санкт-Петербург, 2016) был посвящён хлебу в традиционной культуре. В этом проекте использованы три ритуально-мифологических сценария: человек в «биографии» хлеба, хлеб в биографии человека, обрядовый хлеб внутри годового круга. В результате в центре зала была помещена печь (тоже как образ «оси мира»), которая символизирует очаг и огонь, основной способ преобразования зерна в хлеб и кашу, природы в культуру [2].

- Экспозиция «Как кузнец Ильмаринен свататься ездил» Карельского музея, основанная на противостоянии мужского и женского начал в традиционной культуре на модели путешествия, только мифологического. Фестиваль сена, ядром которого стало состязание в традиционных видах сенокосных работ: косьба, работа граблями, стогометание, а периферией - мастер-классы по народным ремёслам, карельская кухня, этническая музыка [3].

- Проект «Натуральное хозяйство» (Национальный музей Республики Карелия, 2012) был направлен на переосмысление и популяризацию ценностей традиционного образа жизни в контексте современных трендов экологичности. Этнокультурное наследие при этом обнаруживается в настоящем - в продолжающих существовать традициях кулинарии, огородничества, охоты, рыболовства и т. д. В ходе проекта был объявлен народный фотоконкурс «В натуре!», посвящённый современному натуральному хозяйству; сняты образовательные видеоролики о технологиях смолокурения, валяния валенок, изготовления охотничьих лыж и др. [4].

В исследовании О. М. Рындиной о музее и современной этнической культуре выделяется несколько форм культуры этноса, с помощью которых идёт процесс наследования в музеях: фольклор, декоративно-прикладное творчество, ритуал, праздник $[10,28]$. Остановимся на этих формах и существующих музейных практиках подробнее.

1. Фольклор стал одной из форм выражения духовной культуры этноса. В качестве примера можно привести двух номинантов конкурса «Меняющийся музей в меняющемся мире», проводимого Благотворительным фондом В. Потанина. В проекте «Ярмарка ремёсел в средневековой крепости», представленном Государственным историко-архитектурным природно-ландшафтным музеем-заповедником «Изборск» (Псковская область), «музей берёт на себя инициативу организации ярмарки как имиджевого и торгового события, привлекательного для туристов и турфирм» $[4,622]$. Проект Архитектурно-этнографический музея Вологодской области «Семенково» под названием «Право на судьбу» является победителем конкурса «Меняющийся музей в меняющемся мире» (2014). Это проект о людях и судьбах крестьян, живших в Вологодской деревне рубежа XIX-XX веков. Цель проекта - уйти от наиболее распространённого в музеях способа показа жизни крестьян и построить интерьерную экспозицию-избу. Авторы проекта пытались показать жизни и судьбы крестьян, по-новому раскрыть повседневную жизнь северной деревни. Для этого был создан «Антропологический спектакль», разработана интерактивная этнографическая программа «Право на судьбу». Для посетителей была открыта «Школа музейной интерпретации» и подготовлены специалисты, понимающие традицию и умеющие работать с посетителем [5].

2. Сбор коллекций по современному декоративно-прикладному искусству входит в число приоритетов фондовой работы музея. По этой причине музеи лучше всего отражают и этот срез современной этнической культуры. Национальный костюм фокусирует в себе возможности практически всех традиционных ремёсел. В последние годы в музеях России были реализованы проекты по изучению национального костюма:

- Проект «Изобретая моду» (2014) Всероссийского музея декоративно-прикладного и народного искусства - это проект, который был направлен на сотрудничество музеев, дизайнеров, регионального текстильного бизнеса, фешен-индустрии и государственных структур. Особенностью и новизной проекта является выявление роли науки и технических инноваций в эволюции костюма [6].

- Проект Музейно-выставочного центра г. Находки «Этностиль Приморья» в партнёрстве с татаро-башкирской общественной организацией «Туган тел». В коллекциях современных костюмов отразились мотивы разных национальностей, представленных в Приморье. К проекту про- 


\section{Учёные записки}

Комсомольского-на-Амуре государственного технического университета

явили интерес как опытные мастера, так и молодые дизайнеры, изучающие музейные экспонаты, семейные национальные реликвии и подготовившие коллекции современной одежды, сувениры, украшения с национальными мотивами. Фестиваль нарядов в этническом стиле стал лишь частью более обширного замысла об укреплении межнационального сотрудничества и разработке таких его форм, которые были бы интересны молодёжи [7].

- Особого внимания заслуживает музейный проект 2011-2012 гг. «На самом деле рыба - белая и пушистая» Музея изобразительных искусств (г. Комсомольск-на-Амуре). Участники овладевали навыками обработки рыбьей кожи, изготавливали элементы одежды, погружались в атмосферу быта коренного населения Амура [8].

3. Специфика этнической культуры концентрировалась в ритуале: обряд вбирал в себя слово, действие, песню, музыку, танец, вещный мир в виде культовой атрибутики. Музейный праздник становится преемником ритуала. Кроме того, музейный праздник, вовлекая посетителя в действо, превращает зрителя в участника и тем самым усиливает восприятие, подключая к нему мощный канал эмоциональных впечатлений, образность. В 2012-2017 годах в музеях по-прежнему были популярны фольклорные праздники славянского календарного цикла «Масленица», «Иван Купала». Музеефикация нематериального наследия в музее реконструирует элементы праздничнообрядовой сферы, ритуалы, фольклорные традиции. При этом музеи становятся центрами, использующими усилия национально-культурных объединений, центров фольклора и прикладного творчества.

Особое значение приобретают музеи под открытым небом, на базе которых сохраняются объекты наследия. Музеи подобного типа способствуют формированию исторической памяти, являются необходимым звеном в межпоколенческой передаче наследия. К такому типу музеев, как ска́нсен, относятся Архитектурно-этнографический музей «Тальцы», этнографический комплекс «Кезек» музея-заповедника «Томская Писаница». Примером такого типа музеев в Западной Сибири могут считаться Историко-этнографический музей-заповедник «Шушенское», Архитектурноэтнографический музей деревянного зодчества «Ангарская деревня» и другие [9, 233$].$

Таким образом, перед музеями встаёт задача изыскания новых средств и методов работы по трансляции наследия этнокультурного многообразия. Необходимы инновационные подходы. Получило своё развитие и направление, связанное с соединением сегмента развлечений с обучением и культурной средой музея. Перед многими музеями стоит вопрос дальнейшего существования, поэтому продолжают оставаться острыми проблемы посещения музеев и организации форм работы. Произошёл переход от экономики внимания к экономике участия. Всё, что делает музей, должно привлекать и вовлекать. От эпохи потока информации переходим к эпохе вдохновения. Наблюдается использование цифровых медиа в создании музейных технологий, например, разработка виртуальных реконструкций объектов этнокультурного наследия, основанных на методах 3D-моделирования.

За пятилетний период существования новой национальной политики РФ обзор деятельности музеев подчёркивает необходимость сохранения культурного наследия, традиций через инновационные технологии их развития в новых социокультурных условиях, что определяется миссией музеев.

\section{ЛИТЕРАТУРА}

1. Болотина, И. И. Анализ Стратегии государственной национальной политики России до 2025 года // Известия ТулГУ. Гуманитарные науки. - 2016. - № 1. - С. 32-36.

2. Вакулич, Н. Р. Роль музеев в процессе формирования этнической культуры [Электронный ресурс] Н. Р. Вакулич. - Режим доступа: http://tourlib.net/statti_tourism/vakulich.htm (дата обращения: 20.12.2018).

3. Вьят Жермен. Форум: этнографические музеи сегодня / Вьят Жермен // Антропологический форум. 2007. - № 6. - С. 6-40.

4. Денисова, И. В. Зрелищные формы в музее как тенденция современности / И. В. Денисова, Л. С. Именнова // Известия ПГПУ им. В. Г. Белинского. - 2011. - № 24. - С. 622-626. 
Нургалиева М. Б.

РОЛЬ СОВРЕМЕННЫХ МУЗЕЕВ В ФОРМИРОВАНИИ МЕХАНИЗМОВ НАСЛЕДОВАНИЯ ТРАДИЦИЙ

ЭТНОКУЛЬТУРНОГО МНОГООБРАЗИЯ (ПО МАТЕРИАЛАМ РОССИЙСКИХ МУЗЕЕВ ЗА 2012-2017 ГОДЫ)

5. Коваль, С. В. Теоретические особенности взаимодействия местного и национального в музее как подсистеме культуры / С. В. Коваль // Международный научно-исследовательский журнал. - 2017. - № 5(59). C. $75-77$.

6. Кривошеин, А. Н. Роль и место музеев и музейной науки в этнокультурном развитии народов России А. Н. Кривошеин // Вестник Ассоциации вузов туризма и сервиса. - 2012. - № 3. - С. 16-19.

7. Курьянова, Т. С. Музеи Сибири как центры воспроизводства этнокультурных смыслов и практик Т. С. Курьянова // Этнокультурное воспроизводство в условиях глобализации: этноперекрёстки и трансграничье: мат-лы ХІ Конгресса антропологов и этнологов России, Екатеринбург, 2-5 июля 2015 г. - М. - Берлин: Директ-Медиа, 2016. - 316 с.

8. Николаев, О. Р. Традиционный миф в плену у музейного мифа: как музейщикам перестать рассказывать детям «сказки»? / О. Р. Николаев // Музей как пространство образования: игра, диалог, культура участия. Вып. 2. - М., 2015. - 236 с.

9. Пронина, С. А. Подходы к классификации этнографических музеев под открытым небом Сибири С. А. Пронина // Вестник КемГУКИ. - 2018. - № 45. - С. 230-236.

10. Рындина, О. М. Музей и современная этническая культура / О. М. Рындина // Вопросы музеологии. 2010. - № 2. - С. 28-33.

\section{ПРИМЕЧАНИЯ}

1. «Путешествие в страну людиков» - опыт лучшего реализованного проекта. Сайт Благотворительного фонда Владимира Потанина (2012) [Электронный ресурс]. - Режим доступа: http://museum.fondpotanin.ru/novosti/competition/2012-01-27/648603 (дата обращения: 18.12.2018).

2. Форма. Петербургская биеннале музейного дизайна 30.09 - 30.10.2016 [Электронный ресурс]. - Режим доступа: http://spbmuseumdesign.ru/biennale-2016/programme/new-museum-exhibitions/ (дата обращения: 19.12.2018).

3. Выставка «Как кузнец Илмалиннэ свататься ездил». Сайт музея Кондопожского края [Электронный ресурс]. - Режим доступа: http://kondmus.karelia.ru/posetiteljam-i-turisticheskim-kompanijam/proekty/puteshestvie-vstranu-ljudikov/vystavka-kak-kuznec-ilmalinne-svatat-sja-ezdil/ (дата обращения: 18.12.2018).

4. Экспозиция «Натуральное хозяйство». Сайт Национального музея Республики Карелия [Электронный pecypc]. - Режим доступа: http://nmrk.karelia.ru/site/section/781 (дата обращения: 20.12.2018).

5. Дневник проекта «Право на судьбу». Сайт Архитектурно-этнографического музея Вологодской области «Семенково» [Электронный ресурс]. - Режим доступа: https://www.semenkovo.ru/ru/projects/pravo-na-sudbu (дата обращения: 21.12.2018).

6. Изобретая моду: биеннале инновационного текстиля. Сайт Благотворительного фонда Владимира Потанина (2014) [Электронный ресурс]. - Режим доступа: http://museumguide.ru/textilebiennale (дата обращения: 20.12.2018).

7. Проект «Этностиль Приморья» завершится выставкой в музее Находки // ПримаМедиа, 28 сентября 2018 г. [Электронный ресурс]. - Режим доступа: https://primamedia.ru/news/741236/?from=37 (дата обращения: 18.12.2018).

8. Проект «На самом деле - рыба белая и пушистая» приглашает. МУК Комсомольска-на-Амуре «Музей изобразительных искусств» [Электронный ресурс]. - Режим доступа: http://www.kmsmuseum.ru/node/11075 (дата обращения: 22.12.2018). 